\title{
GCU
}

Glasgow Caledonian

University

University for the Common Good

\section{Hand and hand preferences in use of a visual analogue scale}

McKechnie, Jacqui G.; Brodie, Eric E.

Published in:

Perceptual and Motor Skills

DOI:

10.2466/pms.107.3.643-650

Publication date:

2008

Document Version

Author accepted manuscript

Link to publication in ResearchOnline

Citation for published version (Harvard):

McKechnie, JG \& Brodie, EE 2008, 'Hand and hand preferences in use of a visual analogue scale', Perceptual and Motor Skills, vol. 107, no. 3, pp. 643-650. https://doi.org/10.2466/pms.107.3.643-650

\section{General rights}

Copyright and moral rights for the publications made accessible in the public portal are retained by the authors and/or other copyright owners and it is a condition of accessing publications that users recognise and abide by the legal requirements associated with these rights.

Take down policy

If you believe that this document breaches copyright please view our takedown policy at https://edshare.gcu.ac.uk/id/eprint/5179 for details of how to contact us. 
Title: $\quad$ Hand and Hand Preferences in the use of a Visual Analogue Scale.
Authors:
Dr. Jacqui G McKechnie
Dr. Eric E Brodie
Glasgow Caledonian University
Correspondence to: Dr. Jacqui G McKechnie
Department of Psychology,
Glasgow Caledonian University,
Cowcaddens Rd,
Glasgow,
G4 0BA,
UK
Email: $\quad$ jgmc@gcal.ac.uk
Category: $\quad$ original article
Key words: $\quad$ Intensity measurement, Hand preference, Visual Analogue Scale, Pain, Manual response
Short Title: $\quad$ Biases for Visual Analogue Scales




\section{Summary}

Visual analogue scales are commonly used to measure the intensity of sensations and their validity and reliability have been reported. However, biases similar to those found in visual line bisection have not been investigated. 23 right-handed and 19 lefthanded participants, with a mean age of $30.1 \mathrm{yr}$., marked three points on a visual analogue scale representing imagined pain, using both the left and right hands, corresponding to 1/4, $1 / 2$ and $3 / 4$ of the way across the scale. In keeping with visual line bisection literature, both right and left-handed participants marked the scale with the left hand significantly leftward of the point marked with the right hand, thereby under-reporting the intensity. Right-handed participants marked 1/4 significantly leftward and 3/4 significantly rightward of veridical points thereby under-reporting and over-reporting, respectively, the intensity. However, left-handed participants did not display this bias and consistently erred leftward for $1 / 4,1 / 2$ and $3 / 4$ positions, under-reporting intensity. These findings were explained in terms of hemispheric specialisation and activation for a manual response to a visuospatial task, with the conclusion that scoring the visual analogue scale to millimetre accuracy is subject to a potential confound of these factors. 
$\underline{\text { Introduction }}$

Systematic errors found in visual line bisection with use of the dominant hand and the non-dominant hand, the allocation of attention and the marking of points other than the middle, may potentially compromise the use of the visual analogue scale. It is essential to quantify the intensity of a sensation a person is experiencing in a valid and reliable way. The visual analogue scale uses a horizontal line of a predetermined length, usually $100 \mathrm{~mm}$, with flanking words indicating the absence of the sensation at one end of the line and its maximal presence at the other. For pain, which is by far the most common sensation measured on such a scale, the person marks the intensity of the pain on the line, with a pen or pencil. This position is subsequently measured and coded from 0 indicating the absence of pain to 100 , indicating the presence of the most severe pain (Huskisson, 1974; Scott \& Huskisson, 1976; Jensen, Karoly, \& Braver, 1986).

While the visual analogue scale seems straightforward, it may be subject to certain biases such as those which appear when people are asked to bisect lines. Line bisection has been extensively studied (for review see Jewell \& McCourt, 2000); there is a tendency to bisect lines erroneously and mark a point to the left of the midpoint, known as 'pseudoneglect' (Bowers and Heilman, 1980). This literature is relevant when considering an individual's indication of intensity of a sensation on a visual analogue scale. If a moderate sensation is experienced and the person tries to mark the point half way between the ends of the line, there should be a consistent deviation to the left, resulting in underreporting. A number of factors are known, however, to influence significantly the extent of this under-reporting. 
Hand preference has influenced the amount of deviation in line bisection. Sinistrals misbisect a line significantly more to the left than dextrals using their preferred hand (Luh, 1995; Scarisbrick, Tweedy and Kuslansky, 1987) although one recent study did not replicate this finding (Brodie \& Dunn, 2005). This error implies that sinistrals may underreport the sensory intensity compared to dextrals. Because $10-15 \%$ of the population is sinistral (Gilbert and Wysocki, 1992), this underestimation has potentially important implications for their use of visual analogue scales.

The hand used has also influenced the amount of deviation in line bisection. Both sinistral (Brodie \& Dunn, 2005; Scarisbrick, et al., 1987) and dextral participants (Brodie, McKechnie, \& Niven, 2000; Brodie \& Pettigrew, 1996) tend to bisect lines farther to the left when using their left hand, suggesting that participants should use the same hand when repeatedly using the visual analogue scale and that both sinistral and dextral participants should use the right hand to avoid potentially under-reporting their pain.

The allocation of visual attention has also influenced the amount of deviation in visual line bisection. The directional scan adopted from reading tends to be applied to line bisection, with left-to-right readers misbisecting to the left, and right-to-left readers misbisecting to the right (Chokron \& Imbert, 1993; Chokron, Perenin, Rode, \& Imbert, 1993) although there is evidence that left-to-right readers may not significantly deviate to the left when forced to adopt a right to left scan (Brodie \& Pettigrew, 1996). However, because a visual analogue scale has flanking words that have to be read before performing 
the task it seems likely that subjects adopt a left to right attentional scan prior to transecting the line, and make the corresponding deviation, as was the finding by Fischer (1994).

Finally, there is evidence that people make systematic errors marking a line at points other than the midpoint which may have implications for the reporting of mild and severe pain using the visual analogue scale. For example, there is a tendency to underestimate points up to and including the midpoint and to overestimate points above the midpoint (Son, Na, Kwon, Kang, Adair, \& Heilman, 2001). However, in that study, only dextral subjects were tested while using only their right hand and without controlling the direction of scan.

This study assessed whether directional errors are present for a visual analogue scale representing pain when the $1 / 4,1 / 2$ and $3 / 4$ positions are marked, and whether the hand used by participants and their hand preference influence extent and direction of these errors. One expected to find that (a) dextrals will underestimate the $1 / 4$ and $1 / 2$ positions and overestimate the $3 / 4$ position with both hands, (b) sinistrals would underestimate all positions and this would be more marked with the left hand and (c) sinistrals would deviate farther to the left than the dextrals for all ratings.

\section{Method}

Design 
An experimental design with one between subject factor of hand preference with two levels (sinistral, dextral) and two within subjects factors, position (3 levels: 1/4, 1/2, 3/4) and hand (2 levels: left, right) was implemented.

\section{Participants}

Twenty three dextral participants had a mean score on the Edinburgh Handedness Inventory (Oldfield, 1971) of 62.8, and 19 sinistrals a mean score of -70.8 . There were 7 men and 35 women whose ages ranged from 17 - 59 years $(M=30.1$ yr.). All participants were left to right readers who reported normal or corrected to normal vision.

\section{Apparatus}

Booklets were prepared with 24 100mm horizontal trial lines in each and presented in a landscape orientation on A4 paper. The lines were positioned $112 \mathrm{~mm}$ from the top of the page. The centre of the line ranged from 133 to $144 \mathrm{~mm}$ from the left edge of the page to avoid the edge of the page acting as a cue. There was one $1 \mathrm{~mm}$ thick line per sheet, and printed in Times font 14 point were anchors of 'no pain' at the left side of the line and 'severe pain' at the right with a $1 \mathrm{~mm}$ gap. The horizontal orientation was used as this is the most common form of the visual analogue scale.

\section{Procedure}

Prior to the administration of the scale, each participant was tested for hand preference using the Edinburgh Handedness Inventory. The experimenter sat opposite the participant and ensured that the participant's body position remained central to the 
stimulus material. Participants were asked to indicate with pen held in their left or right hand an imaginary pain at three points $(1 / 4,1 / 2$, and $3 / 4)$ on the visual analogue scale. The order and use of left and right hand was randomised, with each position being indicated four times. The participants were asked to read the left flanker followed by the right flanker before marking each point, to ensure the consistent allocation of visual attention across trials. Two practice lines were used initially to judge whether the instructions were clear and to give the participants an opportunity to clarify the procedure. The participants were told that they would not be timed, but were encouraged to perform the task fairly quickly. Deviations from the veridical point, or signed errors, were measured to the nearest millimetre, with errors to the left given a negative value, and errors to the right given a positive value. Absolute or unsigned errors were also recorded.

An analysis of variance was carried out upon the signed errors with hand (left, right) and position $(1 / 4,1 / 2,3 / 4)$ as the within subject factors and handedness (sinistral, dextral) as the between subject factor. This was repeated for unsigned errors.

\section{$\underline{\text { Results }}$}

A significant main effect was found for Hand $\left[F_{1,40}=18.93, p<.001\right]$ due to the mean errors of the left hand $(\mathrm{M}=-1.56 \mathrm{~mm}, \mathrm{SD}=.27)$ being significantly to the left of those for the right hand $(\mathrm{M}=-.52 \mathrm{~mm}, \mathrm{SD}=.23)$; for position $\left[F_{2,80}=11.94, p<.001\right]$ due to the errors for $1 / 4(\mathrm{M}=-2.24 \mathrm{~mm}, \mathrm{SD}=.34), 1 / 2(\mathrm{M}=-1.01 \mathrm{~mm}, \mathrm{SD}=.32)$ and $3 / 4(\mathrm{M}=$ $0.13 \mathrm{~mm}, \mathrm{SD}=.39$ ) significantly differing from each other, and a significant interaction 
between hand preference and position $\left[F_{2,80}=15.83, p<.001\right]$ was found. No other main effects or interactions were significant.

The significant interaction between hand preference and position was due to the errors of sinistrals remaining constant across the three positions whereas the errors for dextrals were significantly different at $1 / 4(\mathrm{M}=-3.57 \mathrm{~mm}, \mathrm{SD}=.46)$ compared to $3 / 4(\mathrm{M}$ $=1.52 \mathrm{~mm}, \mathrm{SD}=.52$ ) (see figure 1). This figure indicates the range, lower and upper quartiles and the median in $\mathrm{mm}$ of the mean directional deviations by preferred hand for dextrals and sinistrals. 
Figure 1: Mean Signed Errors in mm for Ratings of Mild, Moderate and Severe Pain by Hand Preference
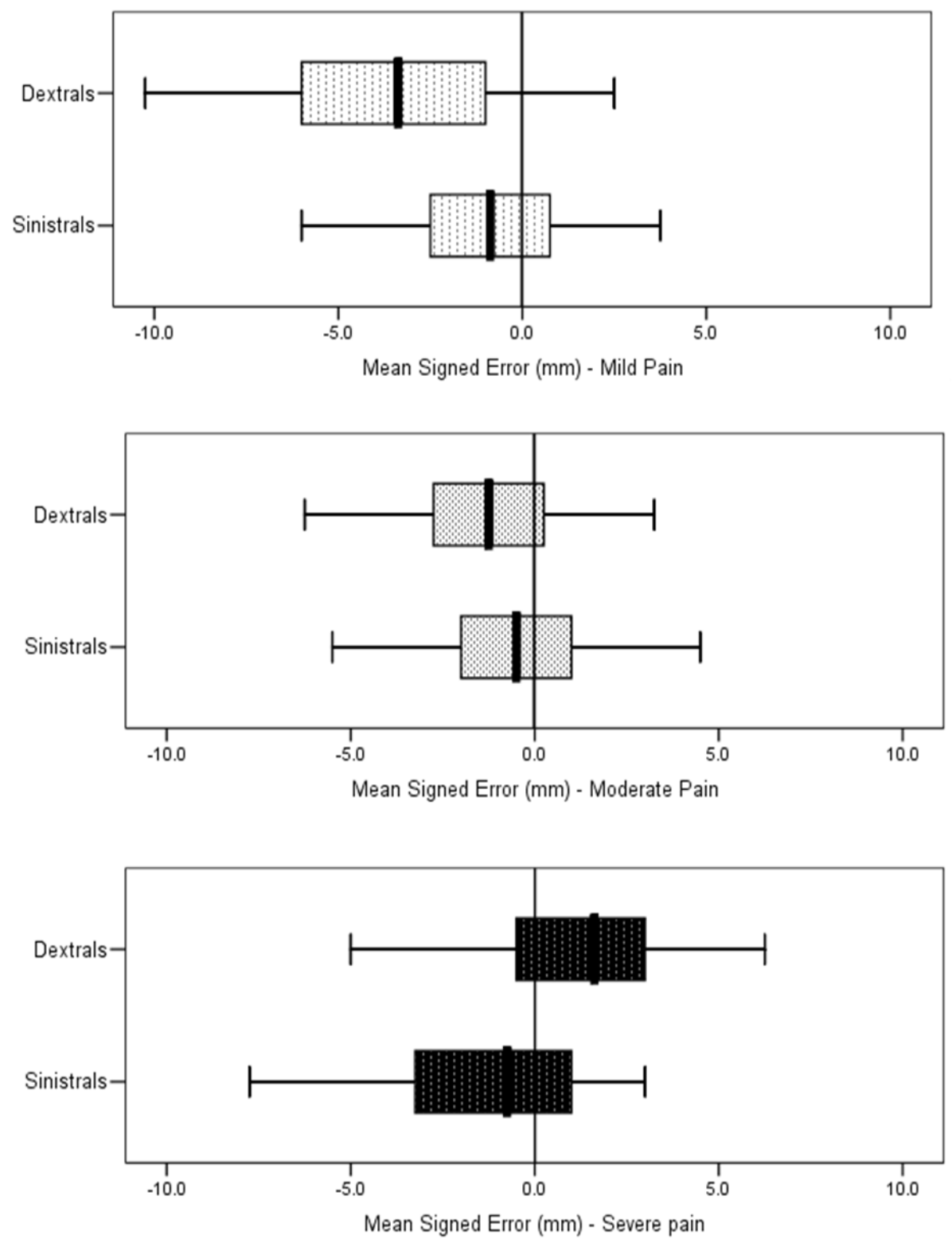

To investigate this further, the signed errors by the left and right hands of sinistrals and dextrals were compared with the veridical points. One sample t tests comparing the biases against zero indicated that the error by the left hand of the sinistrals was found to 
significantly deviate leftward from $1 / 4\left(t_{18}=-2.99, p=.008\right)$ and $1 / 2\left(t_{18}=-2.503, p=\right.$ $.02)$. The error by the left hand for the dextrals was found to deviate significantly leftward for $1 / 4\left(t_{22}=-6.778, p<.001\right)$ and $1 / 2\left(t_{22}=-3.22, p=.004\right)$. The error by the right hand for dextrals deviated significantly leftward for $1 / 4\left(t_{22}=-4.83, p<.001\right)$ and significantly rightward for ratings at $3 / 4\left(t_{22}=3.69, p=.001\right)$. All other signed errors did not significantly deviate from the veridical point.

An analysis of variance was also carried out on the unsigned errors, with the same factors as before. Main effects were found for hand $\left[F_{1,40}=6.53, p=.01\right]$, due to the mean errors of the left hand $(\mathrm{M}=3.09 \mathrm{~mm}, \mathrm{SD}=.23)$ being significantly greater than the right hand $(\mathrm{M}=2.65 \mathrm{~mm}, \mathrm{SD}=.14)$; and position $\left[F_{1,40}=6.37, p=.003\right]$ due to the errors for $1 / 4(\mathrm{M}=3.33 \mathrm{~mm}, \mathrm{SD}=.27)$ and $3 / 4(\mathrm{M}=2.94 \mathrm{~mm}, \mathrm{SD}=.22)$ being significantly greater than those at $1 / 2(\mathrm{M}=2.35 \mathrm{~mm}, \mathrm{SD}=.20)$. A significant interaction was found between hand preference and position $\left[F_{1,40}=6.12, p=.003\right]$. No other main effects or interactions were significant.

The significant interaction between hand preference and position was due to the mean error at $1 / 4$ being greater for dextrals $(M=4.21 \mathrm{~mm}, \mathrm{SD}=.37)$ than sinistrals $(\mathrm{M}=$ $2.44 \mathrm{~mm}, \mathrm{SD}=.41)$ and at $3 / 4$ being greater for dextrals $(\mathrm{M}=3.12 \mathrm{~mm}, \mathrm{SD}=.29)$ than for sinistrals $(\mathrm{M}=2.75 \mathrm{~mm}, \mathrm{SD}=.32)$. 


\section{Discussion}

The results of this study indicate that marking $1 / 4,1 / 2$ and $3 / 4$ positions on a visual analogue scale corresponding to mild $(25 \mathrm{~mm})$, moderate $(50 \mathrm{~mm})$ and severe (75mm) pain, is subject to the same factors that influence errors in visual line bisection. The hand used influences the degree of underreporting, with the left hand resulting in errors to the left of those made by the right hand. This was true for both dextral and sinistral subjects at all positions tested. This is consistent with the previous research investigating the effects on visual line bisection in sinistrals (e.g. Scarisbrick, et al., 1987; Brodie \& Dunn, 2005) and dextrals (e.g. Brodie \& Pettigrew, 1996; Brodie \& Dunn, 2005). Left hand responses are found to be significantly to the left of right hand responses. This means the same hand should be used by participants for repeated assessments. Using the left hand to indicate pain intensity, after rating pain with the right hand, is likely to result in an apparent decrease in the intensity of sensation, which may not have occurred.

In this study, sinistrals did not mark the visual analogue scale more to the left than dextral subjects for all points. This is contrary to the findings of Scarisbrick, et al., (1987), who found that for visual line bisection, sinistral subjects marked the midpoint of the line significantly to the left of dextral subjects. However, their sample size was small $(\mathrm{N}=12$ sinistrals) and scanning direction was not controlled. In a recent visual line bisection study with a larger sample size $(\mathrm{N}=26$ sinistrals) controlling potentially confounding variables, sinistrals did not deviate any more to the left than dextrals (Brodie \& Dunn, 2005). This finding is more in keeping with the less pronounced lateralisation of hemispheric function 
found in sinistrals (Vogel, Bowers, \& Vogel, 2003). Thus sinistral subjects will not underreport the intensity of a sensation any more than dextral subjects.

For dextrals, the direction of the errors differed across the spatial positions on the line attempting to be indicated. Attempting to mark $1 / 4$ resulted in deviations to the left whilst attempting to indicate $3 / 4$ resulted in deviations to the right when using the preferred hand. This is partly in keeping with the findings of Son, et al., (2001) who found that dextrals deviated to the left for ratings of $1 / 4$ and a $1 / 2$ and deviated to the right at $3 / 4$ in a line quadrisection task. The reason dextrals did not deviate significantly to the left at the $1 / 2$ position may be due to the presence of the longer visual analogue scale flanking words to the right of the line. It has been argued that this extends the perceptual extent of the line to the right (Fischer, 1996). This may also explain why the right hand errors of sinistrals were not found to deviate significantly to the left at the $1 / 2$ position as was reported by Brodie \& Dunn (2005) in visual line bisection. Thus, when using the right hand, dextrals may over-report a severe pain and under-report a mild pain whereas sinistrals when using the left hand will be likely to under-report mild, moderate and severe pain intensities.

When the left and right hands of participants were analysed, only when sinistrals used their left hand to mark the $1 / 4$ and $1 / 2$ positions did the errors significantly differ from the veridical position. For dextrals the errors significantly differed at $1 / 4$ for both hands and at $1 / 2$ for the left hand. It was only at $3 / 4$ for the right hand that significantly differed from the veridical point in a rightward direction. These findings may partly be 
exaplained by the hemispheric activation model (Bradshaw, Bradshaw, Nathan, Nettleton, \& Wilson, 1986; Failla, Sheppard, \& Bradshaw, 2003; McCourt, Freeman, TahmahkeraStevens, \& Chausee, 2001). It would be predicted from this model that a unimanual response would selectively activate one hemisphere which leads to an enhancement of the contralateral hemispace. This may explain why dextrals using the right hand tend to make ratings to the left of the veridical point at $1 / 4$ and $1 / 2$, but does not adequately explain why the ratings were rightward at 3/4. Brodie and Dunn's (2005) three factor theory may provide a fuller explanation: unilateral activation of the contralateral hemisphere for a unimanual response; allocation of spatial attention and hemispheric specialisation for spatial functions may all conspire to skew ratings. Dextrals have right hemisphere dominance for spatial functions, have unilateral activation for a unimanual response, and are normally subject to an asymmetrical representation of space that results in a bias to the left. This can be applied to the difference found across conditions, for example, for the 3/4 response, spatial attention is drawn to the right side of the line, while the right hand is used and the flanking words last read are on the right. All of these may lead to activating the left cerebral hemisphere, which results in an over-representation of the right side of the line and a bias to the right of the veridical position. Functional brain imaging would allow this explanation to be confirmed.

Sinistral participants are not subject to right hemisphere dominance or unilateral activation for a unimanual response and so are consistently biased by attentional factors to the left. However, the bias in sinistrals for visual line bisection has also been shown to be able to be moved to the right if their attentional scan is manipulated (Brodie \& Dunn, 
2005). No attempt was made in this study to vary where subjects allocated their visual attention, but consistently ensured first the reading of the left then the right flanker prior to manually responding. Eye tracking would allow the allocation of visual attention to be confirmed.

The present results showed that marking $1 / 4$ and $3 / 4$ is more inaccurate than marking $1 / 2$ as significantly larger unsigned errors were found at the 1/4 and 3/4 positions. In order to quadrisect a line a two stage bisection strategy is likely to be adopted, firstly the whole line is bisected then the resultant half is bisected (Lee, Jeong, Kang, Baeck, Chin, Adair, \& Na, 2004). Thus any bias present at the first stage is carried over to the second. However in this study only dextral subjects were found to be significantly less accurate at marking the $1 / 4$ and $3 / 4$ positions than $1 / 2$. Sinistrals displayed little difference between the unsigned errors across these three spatial positions. Again this can be explained by dextrals being subject to hemispheric asymmetries in visuo-spatial function and for manual activation while sinistrals are not (Brodie \& Dunn, 2005).

In conclusion, the visual analogue scale continues to be used extensively in research and many researchers adopt millimetre accuracy for the measurement of acute and chronic pain intensity (e.g. Bryant, 1993; Linton and Melin, 1998; Usichenko, Edinger, Witstruck, Pavlovic, Zach, Lange, Gizhko, Wendt, Koch, \& Lehmann, 2008) and experimental pain intensity (e.g. Biasiotta, Peddireddy, Wang, Romaniello, Frati, Svensson, \& Arendt-Nielsen, 2007; Schulte, Segerdahl, Graven-Nielsen, \& Grass, 2006; Terry, Brodie, \& Niven, 2007). Caution should therefore, be shown when using the visual 
analogue scale to millimetre accuracy, as there is a potential confound due to hand preference and hand used.

\section{$\underline{\text { References }}$}

Biasiotta, A., Peddireddy, A., Wang, K., Romaniello, A., Frati, A., Svensson, P., \& Arendt-Nielsen, L., (2007) Effect of pinching-evoked pain on jaw-stretch reflexes and exteroceptive suppression periods in healthy subjects. Clinical Neurophysiology, 118(10), 2180-2188.

Bowers, D., \& Heilman, K. M., (1980) Pseudoneglect: effects of hemispace on a tactile line bisection task. Neuropsychologia, 18, 491-498.

Bradshaw, J. L., Bradshaw, J. A., Nathan, G., Nettleton, N. C., \& Wilson, L. E., (1986) Leftwards error in bisecting the gap between two points: stimulus quality and hand effects, Neuropsychologia, 24, 849-55.

Brodie, E. E., \& Dunn, E. M., (2005) Visual line bisection in sinistrals and dextrals as a function of hemispace, hand, and scan direction. Brain and Cognition, 58, 149-156.

Brodie, E. E., McKechnie, J., \& Niven, C. A., (2000) Factors affecting the use of the Visual Analogue Scale in pain intensity measurement. Pain in Europe III: Advances in Pain Research and Therapy, 1, 215. 
Brodie, E. E., \& Pettigrew, L. E. L., (1996) Is left always right? Directional deviations in visual line bisection as a function of hand and initial scanning direction. Neuropsychologia, 34(5), 467-470.

Bryant, R. A., (1993) Memory for pain and affect in chronic pain patients, Pain, 54, 34751.

Chokron, S., \& Imbert, M., (1993) Influence of reading habits on line bisection. Cognitive Brain Research, 1(4), 219-222.

Chokron, S., Perenin, M. T., Rode, G., \& Imbert, M., (1993) Scanning direction and line bisection. Perception, Supplement, 22, 120.

Failla, C. V., Sheppard, D. M., \& Bradshaw, J. L., (2003) Age and responding-hand related changes in performance of neurologically normal subjects on the line-bisection and chimeric-faces tasks. Brain \& Cognition, 53, 353-363.

Fischer, M. H. (1996) Bisection performance indicates spatial word representation. Cognitive Brain Research, 4, 163-170.

Fischer, M. H., (1994) Less attention and more perception in cued line bisection. Brain and Cognition, 25, $24-33$. 
Gilbert, A. N., \& Wysocki, C. J., (1992) Hand preference and age in the United States Neuropsychologia, 30(7), 601-608.

Huskisson, E. C., (1974) Measurement of pain. Lancet 9, 1127-1131.

Jensen, M. P., Karoly, P., \& Braver, S., (1986) The measurement of clinical pain intensity: a comparison of six methods. Pain, 27, 117-26.

Jewell, G., \& McCourt, M. E., (2000) Pseudoneglect: a review and meta-analysis of performance factors in line bisection tasks. Neuropsychologia, 38, 93-110.

Lee, B. H., Jeong, Y., Kang, S. J., Baek, M. J., Chin, J., Adair, J. C., \& Na, D. L., (2004) Visual search pattern during the line quadrisection task in normal subjects. Experimental Brain Research, 156(4), 487-494.

Linton, S. J., \& Melin, L., (1982) The accuracy of remembering chronic pain, Pain, 13, 281-285.

Luh, K. E., (1995) Line bisection and perceptual asymmetries in normal individuals: what you see is not what you get. Neuropsychology, 9, 435-438. 
McCourt, M. E., Freeman, P., Tahmahkera-Stevens, C., \& Chausee, M., (2001) The influence of unimanual response on pseudoneglect magnitiude, Brain and Cognition, 45, 52-63.

Oldfield, R. C., (1971) The assessment and analysis of handedness: The Edinburgh Inventory. Neuropsychologia, 9, 97-114.

Scarisbrick, D. J., Tweedy, J. R., \& Kuslansky, G., (1987) Hand preference and performance effects on line bisection. Neuropsychologia, 25, 695-699.

Schulte, H., Segerdahl, M., Graven-Nielsen, T. \& Grass, S., (2006) Reduction of human experimental muscle pain by alfentanil and morphine. European Journal of Pain, 10, (8), 733-741.

Scott, J., \& Huskisson, E. C., (1976) Graphic representation of pain. Pain, 2, 175-184.

Son, Y., Na, D. L., Kwon, H. M., Kang, Y., Adair, J. C., \& Heilman, K. M., (2001) Line quadrisection errors in normal subjects. Cortex, 37(5), 665-70.

Terry, R., Brodie, E. E., \& Niven, C. A., (2007) Exploring the phenomenology of memory for pain: Is previously experienced acute pain consciously remembered or simply known? The Journal of Pain, 8 (6), 467 - 475. 
Usichenko, T. I., Edinger, H., Witstruck, T., Pavlovic, D., Zach,M., Lange, J., Gizhko, V., Wendt, M., Koch, B. \& Lehmann, C., (2008) Millimetre wave therapy for pain relief after total knee arthroplasty: A randomised controlled trial. European Journal of Pain, 12(5), 617-623.

Vogel, J. L., Bowers, C. A., \& Vogel, D. S., (2003) Cerebral lateralization of spatial abilities: A meta-analysis. Brain and Cognition, 52, 197-204. 